\title{
TIEMPO INDUSTRIAL Y TIEMPOS SOCIALES EN MARÍA ELENA, LA ÚLTIMA CIUDAD DEL SALITRE ${ }^{1}$
}

\author{
INDUSTRIAL AND SOCIAL TIME IN MARÍA ELENA, THE LAST NITRATE TOWN
}

\author{
Juan Carlos Rodríguez Torrent ${ }^{1}$ y Pablo Andrés Miranda Bown ${ }^{2}$
}

\begin{abstract}
En este artículo se plantea, desde el ángulo del trabajo, la precaria condición existencial de los actuales habitantes, trabajadores y ex trabajadores de la ciudad salitrera de María Elena en relación a los soportes culturales identitarios tradicionales. Se centra en las nuevas dinámicas mercantiles y formas de trabajo que se imponen, y su impacto en la identidad y sociabilidad, en la alteración de las confianzas y las certidumbres respecto de la ciudad, y en la emergencia de una cultura del desempleo, más allá de lo que quede en el imaginario de la mítica historia de los trabajadores del salitre.

Palabras claves: identidad, marginalidad, exclusión social, asistencialismo, cultura del trabajo, cambio tecnológico, flexibilidad laboral.

This article deals with the precarious existential condition of present inhabitants, workers and co-workers of the nitrate plant town María Elena, located in the north of Chile. It also refers to the traditional cultural background. It focuses in the new mercantile dynamics and forms of labor that are being imposed and their impact in identity and sociability, as well as in the alteration of confidence and certainty about the town. All this occurs in a "culture of unemployment" beyond the remains of the mythic history of nitrate workers.
\end{abstract}

Key words: Identity, extreme poverty, social exclusion, assistantship, labor culture, technological change, labor flexibility.

\begin{abstract}
¿Y en qué punto me encuentro yo?, no tengo ni ánimo ni lugar adecuado para hacer nada; tampoco me queda mucho tiempo, pero te quiero, Egipto, y perdona si, además del amor que siento por ti, ves que también adoro la vida en estas horas confusas de la despedida al final del trayecto. (Naguib Mahfuz, Amor bajo la lluvia).

$¿ \mathrm{O}$ la dicha de vivir depende de la alquimia retrospectiva que transforma los trabajosos días en amables recuerdos? (Adolfo Bioy Casares, La invención y la trama).
\end{abstract}

La ciudad salitrera de María Elena se ubica a $1.200 \mathrm{msm}$, a $70 \mathrm{~km}$ del puerto de Tocopilla (Figura 1), y su construcción concluyó en 1926, año en el que comienza la explotación salitrera bajo un nuevo sistema productivo denominado Guggenheim, que permite la explotación de caliche de menor ley, duplicando la riqueza potencial de la pampa, frente al antiguo sistema Shanks que operaba sobre caliche de más alta ley, que es el más escaso. La planta entra en producción con una capacidad de
600.000 toneladas métricas anuales, cuatro veces superior a la de la Oficina Chacabuco, la más grande del sistema Shanks (Garcés 1999:67).

El nuevo sistema permite el procesamiento de un gran volumen de caliche a través de un creciente proceso de mecanización y electrificación. Molinos, correas transportadoras, grúas, perforadoras a aire comprimido, el tren eléctrico, tractores y camiones comienzan a reemplazar el esfuerzo físico y a importantes contingentes de trabajadores, a las carretas y mulas que caracterizaban al Shanks.

Hoy, María Elena constituye el último emplazamiento habitacional de la mítica historia del oro blanco, donde la industria del salitre, desafiando todos los pronósticos realizados en distintas décadas del siglo que recién se fue (sobre la viabilidad y rentabilidad de su explotación), se convierte en una empresa reconocida a nivel mundial, diversificada y eficiente, y de alta rentabilidad (SQM 2006).

En términos demográficos, según informaciones proporcionadas por el municipio y la empresa SQM actual dueña del complejo habitacional y la infraestructura, son alrededor de 7.500 sus moradores. Estos

\footnotetext{
Escuela de Diseño de la Facultad de Arquitectura de la Universidad de Valparaíso, juancarlosrodriguezt@ yahoo.com Escuela de Arte de la Pontificia Universidad Católica de Chile, pmirandb@puc.cl
} 




Figura 1. Mapa de la zona, tomado de álbum desierto.

Map of the area, taken from album desert.

deben entenderse como fluctuantes, imprecisos y con claras tendencias a decrecer. Los censos hablan de que en 1930 la habitaban 9.062; en 1940, 9.198; en 1952, 9.686, y en 1960, 9.572 (González Pizarro 2003:274). En 1992 se estimaban 13.660; en 1996, 9.583, y en el año 2000, sólo 7.475².

Esto mismo se ve reflejado en el sistema educativo, donde las cifras son más que claras, estimándose que hay un paso desde unos 5.500 alumnos en el año 1990, a unos 1.500 en el 2.006, los que en sentido estricto sólo pueden ser contabilizados al inicio del año escolar, ya que es corriente y concordante con la cifra antes señalada que muchos grupos familiares migren, producto del cambio de las condiciones laborales y contractuales de los jefes de hogar ${ }^{3}$. A partir de la aplicación de un instrumento estandarizado a 263 hogares (Proyecto Fondecyt 1060092), se deduce que para los próximos años se mantendrá una disminución de la matrícula aunque más moderada en relación al decrecimiento de la población, ya que quienes se van de María Elena tienen menos hijos en edad escolar. 
Se estima que unos 1.200 son los trabajadores directos en las faenas, 400 supervisores y unos 200 externos que ofrecen prestaciones diversas (burocracia municipal, profesionales de la salud y educación, limpieza, alimentación del personal), a lo que se suman trabajadores de empresas contratistas, que elevan la cifra a un número superior a los $4.000^{4}$. Según los censos de población, el índice de masculinidad en 1992 era de 116,34, y en el 2002 se empina a 132,98 (INE 2006).

Los actuales procesos productivos, tecnológicos $\mathrm{y}$ administrativos que posicionan internacionalmente a SQM, la empresa dueña de las pertenencias mineras, se conjugan de manera sui generis con la densidad de la historia, pues, por una parte, aparece el peso mítico que tiene el mundo del salitre en la estructuración de la historia social del país (versión local de la revolución industrial, de las tempranas contradicciones entre capital y trabajo, y de las relaciones capitalistas de producción) y, por otra, lo que significó para los trabajadores, en este caso particular, vivir en una ciudad inventada y concebida en sus más mínimos detalles con todos los recursos e infraestructura para hacer atractiva la vida y concretar un proyecto en un territorio inhóspito y yermo, como el desierto, que hubo de ser conquistado y colonizado en el siglo XIX, y con la cual se da nacimiento a la vivienda obrera.

Ambos antecedentes tienen gran fuerza emotiva para los antiguos habitantes, pero aquella historia está cada vez más lejana y la ciudad ha decaído en relación a su pasado: es más pobre en términos simbólicos y materiales, más porosa y desconocida, y al decir de sus más antiguos moradores menos amistosa y vinculante; ha perdido su coherencia originaria, su sentido de comunidad, su identidad colectiva, su espacio mental demarcatorio, su ligazón con la gesta épica, transformándose poco a poco, día a día, en un campamento de trabajadores.

En este tránsito muchos habitantes pierden sus ejes de referencia simbólicos, sociales, laborales y espaciales. El orden que sustentó a María Elena durante décadas (atraer y contener a trabajadores y familias, para producir) ha desaparecido en medio de decisiones estratégicas que reorientan los objetivos productivos. La antigua ciudad cerrada se altera, está en movimiento, se abre y se contrae con nuevos, intermitentes, desconocidos y, a veces, llamativos habitantes; su estructura se vuelve compartimentada y hermética en sus filiaciones (los de "aquí" y los de "allá", los "antiguos" y los "nuevos", los "empresa", los "contratistas" y los "particulares"), irregular en la composición de quienes habitan sus viviendas, porque cambió la estructura ocupacional, se redefinieron los estatus y se modificaron las condiciones de habitabilidad y servicios que la empresa en un continum temporal brindaba a sus trabajadores y que le otorgaron una importante identidad y estabilidad. Esto, y que da pábulo a un mirar hacia atrás, al reforzamiento mítico de cierta Edad de Oro, en medio de un dubitativo futuro, se extendería y mantendría con cierta estabilidad desde la fundación en 1926 y la gran crisis de 1931 hasta cuando comienza la transformación de la Compañía Salitrera Anglo Lautaro -de capitales norteamericanos- en sociedad mixta con el Estado de Chile -a través de CORFO- en mayo de 1968 (62,5\% frente a 37,5\%), para luego en 1970 la CORFO alcanzar el control de Compañía con el 51\%, y en el mismo año lograr el 70\%. En 1971, el Estado de Chile logra el 100\% de control, para luego ser privatizada en 1988 (Durruti 1993).

Con la privatización se inicia un amplio proceso modernizador (tecnológico, social, laboral, administrativo) que va a la par de la internacionalización y diversificación de la empresa, produciendo un nuevo orden. Pero este orden, que vuelve poroso un universo social muy regulado y entrópico bajo administración norteamericana, y estable en términos laborales y de beneficios en la administración mixta y estatal, nunca ha sido gratuito y conduce "a ciertas partes de la población existente al papel de fuera de lugar, no aptas e indeseables" y, al mismo tiempo, el progreso económico es "incapaz de proceder sin degradar y devaluar los modos de ganarse la vida antaño efectivos..." (Bauman 2005:16). Hay muchos modos posibles de ver y situarse frente al tiempo y la historia, porque se viven y padecen de manera disímil.

En este sentido, actualmente la experiencia local es parte de la universal lógica de la modernidad, que en su proyecto provoca condiciones residuales, indeseables e innecesarias y deja en zonas grises a muchas personas. La producción del orden moderno instala tal condición y María Elena es sólo una experiencia local más en la que algunos trabajadores ya no son necesarios para producir riqueza ni pueden acceder a los beneficios derivados de ella. Así, la dinámica de la innovación tecnológica, la diversificación productiva y la constante superación de sus procesos, deja a su paso ciudades-cementerio, ruinas, vaciadas de su densidad simbólica, siendo la 
"Pampa del Mirage" el territorio de la más reciente de las tragedias de la industria del salitre.

Surge, entonces, a partir del nuevo orden, la marginalidad, la exclusión y el asistencialismo como una práctica recurrente, en una época, en unas condiciones, que marcarían "el fin de una era histórica" (González Pizarro 2005), de una cultura del trabajo en la que coincidieron ciudad y emplazamiento industrial, trabajadores y familias, una fórmula espaciocentrica posible en la medida que el proyecto global se constituye con "abstracción del medio físico en que se sitúa" (Garcés 1999:73) y que posibilita la existencia localizada de sueños individuales y colectivos.

\section{Elementos de Delimitación}

Las transformaciones más significativas que pueden acontecer hoy en el seno de una cultura -cualesquiera sean las escalas de análisis y los particularismos que entrañen, las definiciones que hombres y mujeres den de sí mismos, la magnitud de los miembros que la conforman, las especializaciones productivas que le dan consistencia a su identidad y las tradiciones que articulan el pasado con el presente- arrastran consigo dos cuestiones que son transversales en las dinámicas sociales, económicas, políticas y comunicacionales en el proyecto político dominante.

Una de ellas es el cambio tecnológico en el proceso productivo y su impacto en la estructura ocupacional y demográfica. En María Elena las personas de 60 o más años llegan a 3,56\%, lo que ubica a la Comuna con el índice de vejez más bajo del país (Censo de Población 2002). Esto indica la transformación de la ciudad y la imposición y posicionamiento estructural y estructurante de nuevas formas de trabajo, más flexibles, temporales, demandantes de nuevas habilidades y códigos, muchas de ellas deslocalizadas y externalizadas, como también decisiones pragmáticas (desde la lógica empresarial) que hacen prescindentes algunas actividades y especializaciones, más allá del arraigo y reconocimiento que puedan tener o hayan tenido en el tiempo y el espacio. Se trata de un cambio que desarticula redes y activa otras, que impone nuevos códigos y desacredita otros; lo que la conforma actualmente sólo como un lugar para ir a trabajar y no para residir en la etapa posproductiva de sus habitantes.

La otra se refiere a la consolidación de nuevos medios de comunicación de masas como inductores y promotores de lo deseable y como generadores de nuevos intereses, al ampliar las expectativas de consumo y de posibilidades de vida, que dan cuenta de formas variadas de penetración de la complejidad de la urbe, y nuevos insumos y relatos, en aquellos espacios comunitarios que puedan considerarse tradicionalmente cerrados o en aislamiento relativo, y que se cristalizan como fuente de nuevas expectativas y deseos, la mayor de las veces con carácter volátil, pasajero, hedónico e, inclusive, de difícil codificación simbólica por parte de quienes los asumen y recrean.

El goce de un relativo aislamiento simbólico y geográfico ofrecía estabilidad e identidad a los habitantes de ME respecto de una imagen coherente de sí mismos, dimensiones que hoy se ven asediadas y sobrepasadas por las presiones articuladas desde estos dos ejes, refigurando su propia imagen y las redes sociales que le dan estabilidad, confianza e identidad.

\section{Producción y Relaciones Laborales en los Marcos de una Comunidad Especializada}

Al tratar con comunidades especializadas y con un locus de recursos específicos, hablamos de una cultura del trabajo, y ahí debe observarse cómo se posiciona la globalidad en la localidad y cómo la localidad se vincula con la globalidad, es decir, el qué producir, cuánto producir y cómo producir implica un desborde, un necesario reacomodo de las estructuras y dinámicas societarias tradicionales en el orden de los ejes del tiempo y el espacio, y una no despreciable metamorfosis del trabajo y las culturas relacionadas con él, cuestión no menor, si entendemos que la historia individual y colectiva se da dentro de un espacio definido, tanto social (la ciudad u "oficina") como geográfico (el desierto), una especialización productiva (el nitrato) y con escasas posibilidades de diversificación, que se expresa en un modo de vivir y con normas definidas que contienen la desviación de los trabajadores y sus familiares (el reglamento interno), donde la empresa es la dueña de toda la infraestructura urbana y de gran parte del territorio.

En particular, el reglamento ${ }^{5}$ en el sistema productivo Guggenheim -a diferencia del Shanksse perfila como un elemento central que define el espíritu nuevo de las relaciones laborales, ya que su marco general se da en el contexto de la implementación del Código del Trabajo (1931). Por 
tanto, los reglamentos específicos de cada empresa gestados a partir de los años 30, son coherentes con el marco regulatorio vigente. Entonces, es con la administración norteamericana que se "internaliza" la noción de Bienestar Social Integrado, "concepto que involucraba asumir de modo conjunto la higiene, la recreación y los espacios deportivos, como las áreas destinadas a auspiciar las actividades culturales, que gravitaron significativamente en el constructo de la sociabilidad que había operado en la pampa salitrera..." (González Pizarro 2003:230-231; véase también Revista Pampa No 58, 1953: 2-7). La larga recurrencia de esta internalización frente a su declinación a partir de la privatización en el año 1988 es lo que más da consistencia al sentimiento de pérdida de los habitantes más antiguos, ya marginales a la actual cultura del trabajo.

En este sentido, entenderemos por culturas del trabajo aquellas formas simbólicas, apropiadas subjetivamente y expresadas en un espacio social, que definen un entorno en el que se experimentan relaciones de trabajo; en este espacio se cristaliza el proceso laboral, como también la reproducción y la acción social entre los actores (Guadarrama 2002). Esto implica el reconocimiento e identificación de un repertorio específico y limitado de roles, acompañados -en el caso del trabajo del salitre- de un habla particular, en el cual los trabajadores pueden reconocerse como miembros de una cultura o subcultura ocupacional, distinguiendo prestigios, jerarquías, competencias, calificaciones $\mathrm{y}$ experiencias.

Particularmente, hoy en ME, en términos antropológicos y sociológicos, el cómo producir define -por sobre todo- una nueva estructura ocupacional, que se expresa en el fin del pleno empleo y simultáneamente en una constricción y ampliación de los roles históricamente conocidos, desapareciendo antiguas especializaciones-ligadas principalmente al esfuerzo físico- y surgiendo otras, nuevas y de mayor calificación. Asimismo, ello se formaliza en una temporalidad diferente, en la que los tiempos productivos (nuevos sistemas de turnos) modifican los tiempos sociales, familiares e individuales, y la relación con la ciudad y la sociabilidad, lo que obliga a replantearse estos ámbitos del quehacer con las nuevas segmentaciones que esta dimensión alcanza.

De modo genérico, y desde la perspectiva de la industria minera, la modernización y transformación de las tradiciones laborales, viene dada por nuevas formas de organización del trabajo y la introducción de tecnología de punta, avalada por el ingente cambio de la tecnología a nivel mundial, desarrollo de nuevos productos y alta difusión del capital minero. Su impacto se expresa en múltiples aspectos, como la fuerza de trabajo, destacando la localización de la misma (la no necesaria coincidencia entre locus residencial y laboral), la calidad y la cantidad. En este marco, la relación es inversa entre tecnología y cantidad de trabajadores: a mayor y más potente tecnología, menor cantidad de trabajadores (Bauman 2003, 2005; Guerrero 1998), cuestión que, en el caso de la industria salitrera, se expresa hoy, por ejemplo, en la inexistencia de las cuadrillas que daban forma al frente de explotación, aquellas que resaltan las antiguas fotografías tanto del sistema Shanks como del Guggenheim, donde sólo en este último para operar la draga se necesitaban 45 trabajadores, y hoy sólo seis (Rodríguez et al. 2005).

Don José, oriundo de Río Hurtado y con 36 años en María Elena, señala:

Éramos como setecientos [trabajadores] en la pura Casa de Fuerza, entre María, Coya y Pedro [...] Ahora basta uno por turno para que atienda el tablero [...] Imagínese no más, la cantidad de trenes que había. Ahora todo por la correa transportadora"6.

Esta diferencia cuantitativa habla claramente del desarrollo tecnológico, el declive del trabajo manual y la mayor especialización de la fuerza de trabajo para la explotación del nitrato en la explanada del Desierto de Atacama, actividad que sostuvo al erario nacional y condujo a dar forma al poblamiento y las rutas que comunicaron el desierto ${ }^{7}$. Pero lo significativo no es tan sólo la disminución de la plantilla, sino el paso de un trabajo sucio (metafóricamente de manos engrasadas) a uno limpio (de técnicos uniformados) y, sobre todo, la flexibilización que esta tiene, en la medida en que el número "exacto" de trabajadores requeridos está dado por dos ejes simultáneos: por una parte, un núcleo estable, caracterizado por una identificación de las experticias y su flexibilidad funcional, miembros de la empresa SQM; por otra, de una fuerza de trabajo periférica, que revela los márgenes de una flexibilidad numérica, correspondiente a empresas contratistas que prestan sus servicios a SQM. Es decir, los trabajadores estables dan cuenta de calificaciones y capacidades diversas que se reacomodan al interior del proceso 
productivo, mientras que los periféricos sólo son requeridos cuando una coyuntura o los nuevos proyectos así lo exigen (Gorz 1991:89).

De modo que lo que se produce a partir de este juego es una importante modificación de la estructura de oportunidades y una limitación y condicionamiento de las elecciones posibles al interior de una cultura del trabajo; el trabajo es nuevo, es otro. Ello obliga a plantearse -tanto para la empresa, el municipio, el Estado y los investigadores- el problema de la seguridad laboral, de la disponibilidad de recursos para la sobrevivencia y de la emergencia de una cultura del desempleo, en un lugar que se fundó y desarrolló sobre la base del pleno empleo, y donde no existen más alternativas laborales ni posibilidades de diversificación por cuestiones ambientales y porque la ciudad y todo lo adyacente es un territorio privado, propiedad de SQM.

Paralelamente, se establece una gran reorientación de la concepción de la ciudad y de lo que proporcionó sentido a su existencia (al atraer tempranamente trabajadores a un lugar que se inventó en medio de la nada) en la medida en que avanza hacia un campamento minero moderno que desdibuja una cierta idea de comunidad y de la imagen que tienen de sí mismos los eleninos. Así, sobre la base de información del Censo del año 2002, el Observatorio Urbano del Ministerio de Vivienda y Urbanismo señala que la tasa anual de formación de hogares es negativa, llegando a $-5,34 \%$.

Esto significa que hoy, en términos fácticos, desaparece la idea del proyecto vital ligado a la ciudad, ya que mucha de la orientación empresarial se liga al trabajador y no a la familia ni al "bienestar social"; los barrios se descomponen al perder a los vecinos que han debido partir, algunas casas se encuentran vacías, otras sólo con trabajadores solteros, exactamente lo contrario que experimentaron las antiguas generaciones que llegaron con sus familias o la formaron ahí. Ya no es necesario contar con todo lo que ofrecía la antigua ciudad para retener al trabajador, porque las vías de comunicación se han vuelto más expeditas para llegar $a$ y desde los otros centros poblados, y porque no ha sido difícil construir o redefinir nuevos sectores habitacionales para trabajadores solteros en concordancia con los sistemas de turnos ${ }^{8}$, o disponer de antiguas viviendas familiares para trabajadores externos. Éstos no tienen intención de quedarse ni de formar familia en ME ni tampoco es política de la empresa que así sea.
En términos sociales y culturales, lo señalado se vuelve simbólicamente problemático cuando se observa que el trabajo en la cultura del salitre produjo una identidad rígida frente $a$ otros actores sociales y también reconocida desde otros actores y sujetos, que permitió la autodefinición local de pampino y pampina frente a la universal de obrero (González Miranda 2002:37); pero, además, la adscripción a una Oficina o ciudad del salitre, que se expresó en el uso extremadamente simbólico de los gentilicios pertinentes para identificarse y presentarse.

En el caso específico de María Elena -cuya identidad se ve sustentada, además, por una ética moralizante de tipo $\mathrm{WASP}^{9}$ durante la administración norteamericana autónoma desde la fundación del pueblo hasta la chilenización o conversión en empresa mixta en mayo de 1968, que en la perspectiva del tiempo reforzó la cultura del trabajo y cerró el mundo más que abrirlo- podemos sostener que hay elementos en la reformulación de su organización social que llevan a sostener una desterritorialización de esta identidad.

Entendemos por ética WASP aquella que conlleva una moral blanca, anglosajona y protestante, sustentada en un alto compromiso y sentido del deber en el trabajo, tanto con los compañeros como con la Compañía, y desde donde se construye la comunidad de intereses.

Apela a un sindicalismo distante del marco en el que se desarrolla el mundo salitrero en relación a los partidos populares, y con la reiteración en todos los espacios de que la Compañía "entrega lo mejor de sî", inclusive "a cuesta de sus propias utilidades", para que los obreros y sus familias tengan la mejor calidad de vida, como lo han llegado a tener los obreros norteamericanos, incluidos "los negros". Estar ahí, acogido, es ser un "trabajador privilegiado". "Pedagógicamente y discursivamente la empresa descalifica a los trabajadores ineficientes [...] a todos aquellos que no realizan bien las obligaciones y que ponen en riesgo la seguridad de los demás o retrasan el proceso productivo, lo que ayuda a regular con mucha eficacia los elementos de ascenso de sus trabajadores y los beneficios que alcanzan" (Rodríguez 2003:130).

Por tanto, la moral WASP tiene que ver con un sentido del deber y modos de comportarse, con el reconocer que se tiene un lugar en la estructura social y ocupacional, que implica una lealtad al orden prefijado por la Compañía. Ello, dentro de esta lógica, conduce a la "felicidad", y para ello 
hay que ser autoexigente y no conformarse con poco; el trabajo, finalmente -dentro de esta perspectiva- recompensa no sólo materialmente, sino que dignifica y produce un reconocimiento por parte de los demás.

Así, el trabajo otorga a hombres y mujeres una identidad personal, les da visibilidad y reconocimiento, les adscribe una posición social e, inclusive, urbanística en la división territorial de los barrios, facilitando la supervivencia individual y colectiva, reforzando el orden social y la reproducción del sistema. En perspectiva, esto es lo que se extraña, porque era un mundo conocido, con límites espaciales y mentales que se podía dominar y recorrer, otorgando seguridad y confianza, porque "no habían [sic] desconocidos". De modo que, "Comprender la vida en las Oficinas salitreras es acercarse a ver cómo se transforma el paisaje del páramo en un asiento del esfuerzo humano. Se viene a trabajar y después a vivir" (González Pizarro 2003:305); cuestión que, al decir de Sergio González Miranda (2006), hacía coincidir los límites mentales con los límites físicos de las oficinas.

En este sentido, como bien sostiene Robert Castel (1999:15), el problema de los "reajustes laborales" se releva y jerarquiza, porque hay una importante correlación entre el lugar ocupado en la división social del trabajo, la participación en las redes de sociabilidad y los sistemas de protección que ayudan a sobrellevar las vicisitudes que cubren a los individuos de los riesgos. Y cuando estos cambios se manifiestan (nuevos sistemas de turnos, emergencia de otros actores, nueva residencia) son los soportes mismos en los que se suspende la existencia los que se alteran, y éstos, en gran medida, son los que precipitan la disolución de los elementos adscriptivos y filiales, y el debilitamiento de la memoria y su carga histórica, épica y emotiva.

Los cambios tecnológicos y la flexibilidad de los procesos de producción potencian la capacidad productiva de la fuerza de trabajo y los márgenes de plusvalía que se pueden alcanzar. Pero, además, si se demandan experticias adicionales y no habidas en el emplazamiento habitacional tradicional, se consolida rápidamente una cultura del desempleo y del reemplazo de los trabajadores. Pero los individuos pierden mucho más que un empleo cuando se quedan sin trabajo o no pueden hallar uno dentro de sus dominios de experticidad, ya que existe la amenaza de quedar excluidos de la propia sociedad, en la medida en que son exiguas las posibilidades de reintegrarse a ella (Godelier 1998). Sólo así, el cómo producir revela el alcance de su impacto, ya que "deja a individuos en una situación de flotación en la estructura social" (Castel 1999), entendiendo que no tienen lugar asignado y que, inclusive, para ser considerados explotados, sus experticias deben ser reconocidas como "valores sociales" (Castel 1999).

En la actualidad, muchos no tienen ni pueden alcanzar tal condición. A ellos los hemos llamado beautiful losers (Miranda y Rodríguez 2006), porque sólo pueden mirar preterizando estéticamente el futuro, situándose en relación al espacio estable que conocieron, a la ciudad que coincidía con la fuente laboral plena, pero viviendo ya de espaldas al sol, recluidos en su propia historia, delirando con el pasado. Y en María Elena, por cuestiones de propiedad de los terrenos (la ciudad y su infraestructura, ya que hombres y mujeres no son dueños de nada inmueble) y por cuestiones ambientales, ni siquiera existe la posibilidad de diversificarse para quienes han quedado desempleados, y asumir otros roles y reconvertir la identidad y encontrar un lugar en la pampa.

El modelo, para ser eficiente, viable, dinámico y competitivo debe "desengrasar" las empresas; reducir costos, aumentar la productividad del trabajo en el juego de los trabajadores internos y externos, disminuir el número de los que trabajan y aumentar los niveles de desempleo. Sólo que, lo que se espera que sea transitorio, se vuelve permanente (Godelier 1998) y muchos "ni encajan ni se les puede encajar en la forma diseñada" (Bauman 2005:46).

Con ello comienza una singular asistencia social, proporcionada por un Municipio que se encuentra emplazado en un terreno privado ${ }^{10} \mathrm{y}$ expresada en el trienio 2000, 2001, 2002 en una trasferencia de recursos al área social de $\$ 197.770 .173, \$ 105.461 .471$ y \$189.298.242, respectivamente. Sólo el año 2002 destacan entre otros ítems: \$ 117.292.000 en subsidios habitacionales; $\$ 29.389 .836$ en subsidio único familiar; \$ 15.300 .000 , en pensiones asistenciales; $\$ 12.206 .304$, en subsidios de cesantía y $\$ 8.580 .000$ en bonos solidarios del Programa Puente ${ }^{11}$. El año 2005, el gasto municipal por habitante llega a 252,3 (expresado en miles) entre las comunas de más de 5.000 habitantes, cifra sólo superada por comunas como Santiago, Las Condes, Providencia, Vitacura y Algarrobo (Observatorio Urbano MINVU). Pero estas cifras no integran lo que la empresa subsidia en forma directa e indirecta a sus trabajadores y sus 
familias, como a aquellos que ya no lo son, a los funcionarios municipales y de servicios, a través del agua, la luz y la vivienda ${ }^{12}$.

Dentro de esta situación, al señor Alcalde, como representante del Estado, le corresponde hacerse cargo de las vidas mínimas que quedan en la zona gris, en la zona de exclusión, de los inempleados e inempleables. Por eso, la ex Escuela Consolidada, una gran construcción declarada Monumento Nacional, se convierte en un "conventillo" en el que viven por años más de una treintena de niños $\mathrm{y}$ adultos, en el marco de una precariedad absoluta, asistidos permanentemente, con adultos que irregularmente no logran remontar el ingreso mínimo. La condición de estos habitantes en algunos casos se prolonga por más de 10 años, sin posibilidades de desplazamiento hacia otros lugares ni interés por hacerlo $^{13}$. Asimismo, la empresa, el municipio y los eleninos hablan de "barrio chino" para referirse a un sector que ya no sólo tiene características de zona gris, sino de "hoyo negro" por lo indescifrable y estigmatizado.

\section{De Productores a Consumidores}

La cultura del trabajo del salitre es fuertemente cuestionada hoy al debilitarse la experiencia propia de éste como referente de pertenencia, ligada a la identificación de la gesta de los orígenes que permitía responderse quiénes somos y de dónde venimos. Desde la flexibilidad laboral que se impone, de los que quedan dentro y fuera del espectro del trabajo, de los ocupados funcionales y aleatorios, debemos observar el paso de una condición de una comunidad de productores adscritos a referentes simbólicos muy específicos como los políticos, culturales, sociales, recreacionales y literarios, a una de consumidores comprometidos con otros asociados a una condición más global y heterogénea. En ME a diferencia del pasado hay sólo una referencia tangencial con la cultura pampina, pues no están en ella ni llegan para quedarse como continuadores de ella. En las últimas dos décadas el horizonte de construcción de la vida y la identidad deja de estar ubicada en el dominio del trabajo, en lo que se sabe y sabía hacer, como cuestión de conciencia colectiva, sino en el camino del consumo individual, que es donde se alcanzan las mayores cristalizaciones que configuran la identidad y se da la autorrealización y autogratificación.

Para gran parte de los trabajadores directos e indirectos de SQM, el trabajo es sentido como transitorio e, inclusive, coyuntural. Esto vale también para los profesores que ven disminuir año a año la matrícula y amenazada su fuente laboral, como también los trabajadores de la salud y la burocracia municipal. Por lo mismo, para todos ellos, sin posibilidades de proyectarse en el trabajo -y extensivamente en la ciudad-, éste deja de ser el centro, es decir, aquello en el cual se concentran los esfuerzos para constituirse individual y colectivamente, lo que los aparta definitivamente de la memoria y tradición ligadas a gestas heroicas, que posicionaron una identidad mítica en el imaginario popular del país.

Lo señalado es particularmente evidente cuando se producen cambios drásticos en el universo de la organización de los sistemas de turnos, que implican, por ejemplo, jornadas de 12 horas de labor durante una semana, y siete días de descanso. Nueva condición que, por un lado, desde la perspectiva de la empresa, habla de la indesmentible búsqueda de eficiencia y optimización de recursos humanos y materiales (una de las modalidades de la flexibilidad), en pos de una mayor rentabilidad y una aproximación a la plantilla ideal de trabajadores; por otro, del impacto entre muchos de los trabajadores y las familias en relación al tiempo compartido, y de la alteración del vínculo social entre trabajo y locus residencial, de nuevas formas de consumo y de la modificación en los patrones de convivencia, las relaciones y el uso del tiempo libre (v.gr. existen actualmente en María Elena cuatro compañías operadoras de TV cable).

Se vive con altas cuotas de incerteza, precariamente.

En María Elena el personal administrativo de la empresa SQM trabaja de lunes a jueves. Otros trabajadores calificados abandonan la ciudad el día jueves o viernes, porque -más allá de la política de turnos y de ocupación de las viviendas por parte de SQM- la ciudad no ofrece nada que los pueda retener en ella. Sus destinos son diversos: Antofagasta, Tocopilla, Ovalle, La Serena, Coquimbo. Un bus con estudiantes llega los días viernes desde Antofagasta. Por eso, la ciudad se abre y se transforma, otorgando nuevos elementos para contrastar una sugerencia anterior: lo que queda de la cultura se desterritorializa, factor que se potencia cuando muchas actividades imprescindibles para los objetivos empresariales se desarrollan de manera tangencial con la ciudad, la que durante décadas ha sido el soporte habitacional para el funcionamiento de la empresa salitrera, muy particularmente en el caso de empresas contratistas 
vinculadas ocasionalmente para proyectos específicos y con tiempos definidos. Por ejemplo, algunas de éstas tienen un sistema de trabajo de 20 días x 10 de descanso, lo que abre la ciudad al tránsito físico de estos otros trabajadores y a conexiones específicas desde la perspectiva de los eleninos con residencia permanente, las que oscilan entre la desconfianza y la bienvenida. Se espera que, con el fin de algunos proyectos en ejecución, a marzo del año 2007 se eliminen unas 600 plazas de trabajo de empresas que prestan trabajos a SQM.

En virtud de lo anterior, los procesos de cambio derivados no pueden ser enfrentados analíticamente sólo desde la perspectiva de lo económico o en su pura hegemonía. Estas nuevas fuerzas y condiciones socioproductivas que se despliegan en el día a día, se constituyen como representaciones sociales estructurantes que abren la vida a nuevos mundos (reales o imaginarios) y ligan -en los espacios laborales especializados- el trabajo y sus prácticas a esferas que la sobrepasan y que se ubican fuera de ella, como son el sindicato, la familia, las relaciones interpersonales, la vivienda, el barrio, la recreación, la autoimagen, la escuela, las normas, el componente demográfico y, sobre todo, en la sociabilidad y la ritualidad que da consistencia al tejido social.

En este sentido, se abre un espacio para el análisis semiológico y de nuevos marcadores sociales e identitarios, en la medida en que el "just in time" no provoca una necesaria identificación con los fines de la empresa, tal como lo hubo en el pasado a través de la política del "bienestar social" y la coincidencia del locus residencial y laboral en un marco de pleno empleo, o al menos se vuelve discutible. Pero sí revela para muchos trabajadores que su vida se tensiona, y expresa, desde las pérdidas simbólicas y materiales, poca satisfacción entre aquellos que aún creen que se vive en una ciudad que hace años avanza a la estructura de un campamento. La imagen colectiva se disuelve entre trabajadores "empresa", "contratistas" y "particulares; siendo estos últimos, un conjunto de ex trabajadores que no tienen dónde ir, y los más resistentes a abandonar la ciudad, ya que a pesar de la precariedad les resulta económico vivir en la medida que existe un conjunto de subsidios cruzados como vivienda, luz, agua y ayuda del municipio.

Lo antiguo hace tiempo murió; sólo quedan objetos, fotografías y los relatos espasmódicos y agónicos de los más viejos. Tanto así, que el principal producto de interés ya no es el salitre, sino el yodo y el litio, desplazando el énfasis del qué producir. El nuevo orden usurpó la continuidad de una memoria cuyo eje es el trabajo y de un tiempo pletórico de eventos y luchas; los cambios se llevaron la seguridad, la vieja identidad, el deporte, el baile, las galas, las reinas de las fiestas del salitre y de la primavera, los desfiles, el cuadro blanco, el Instituto Chileno Norteamericano de Cultura, la filarmónica, el teatro, el cine, a los "gringos", y ahora se lleva a las familias, desafiliándolas de la sociabilidad construida en la urbe. Y de lo que queda en términos de memoria, mucho huele a cadáver o a "territorio sin mapa" (Rodríguez et al. 2005), a un pasado que no tiene lugar en el presente. Como señala Maurice Godelier: "Sin dinero, sin recursos, [y sin trabajo, agregaremos] no hay existencia social y, en última instancia, ni siquiera existencia a secas, ya sea material o psíquica" (Godelier 1998:12).

En este enclave salitrero, isla en medio del desierto, ya no será lo mismo ser pobre en relación a una sociedad de productores y asalariados que acoge y da razones para vivir colectivamente, de pensar en conjunto, a una de consumidores que encierra al trabajador en sus propias aspiraciones y sin una memoria con un imaginario épico. Pero, no se trata sólo del consumir más o menos (cable, videos, automóviles, celulares), sino que ello implica, como transformación cultural y social, manejar un tiempo que debe ser partido y llenado por cada habitante con nuevas fórmulas, y que obedece a una experiencia nueva: porque el tiempo industrial se impone sobre los tiempos sociales y familiares.

\section{Tiempo Industrial y Memoria}

En el caso de las ciudades del salitre de María Elena y Pedro de Valdivia, durante varias décadas la norma fue el pleno empleo para sus habitantes y con una disposición empresarial -desde sus respectivas aperturas hasta la privatización en 1988-que adoptaba las características de una empresa benefactora que garantizaba la supervivencia (bienestar social), ya que otorgaba la vivienda, la alimentación, el trabajo y los servicios básicos y asistenciales para retener y facilitar la vida a sus trabajadores y familias. Esto debe entenderse desde la misma concepción de ciudad que inspiró su desarrollo, ya que fue pensada y concebida

como medio de producción, buscando máxima concentración de capital y 
trabajo necesaria [sic] para la extracción y procesamiento de los recursos, y organizados en forma autónoma en el territorio. Cada oficina contaba con instalaciones industriales, equipamientos y viviendas, división funcional que ya anunciaba las propuestas para la ciudad moderna que más tarde hizo suyas la Carta de Atenas (Garcés 1999:11).

Fue un requisito para la permanencia en la ciudad tener una plaza de trabajo, la que era dispensada o permitida por el único empleador, por lo que aún en el escenario de menor calificación, lo que hacía cada trabajador tenía valor social; fueron ciudades de productores en las que, inclusive, se podía vivir sin manejar dinero efectivo. Todos sus habitantes contribuían a dos cuestiones que siempre estuvieron enlazadas: industria y ciudad, pues dependían simbiótica y sinérgicamente para sus respectivas existencias. Luego de la privatización, comenzó a cambiar la regla del pleno empleo, se introdujo la flexibilidad y se restringieron las expresiones benefactoras (como el cierre de la pulpería) que fortalecían la autonomía e identidad; el impacto de este cambio se hace sentir al menos en cuatro grandes ejes: (a) la emergencia de nuevos roles, (b) el recambio y disminución de la población, (c) la presencia de cesantes y (d) la aparición de la marginalidad.

En una primera aproximación y en los marcos de lo que fuera una cultura del trabajo, el descenso en la plantilla de trabajadores, y la presencia de los desempleados, los inempleables o los que son simplemente "periféricos", nos habla de un impacto en varias direcciones, ya que se enlazan cuestiones de orden personal y social. Ante todo, porque antes no había necesidad de plantearse "otro trabajo", ya que -en su mayoría- los roles podían ser cubiertos localmente, por lo que la modificación del rasgo de contención de la cultura del trabajo debería ser definido y pensado dentro de un espectro emergente de marcadores que conducen a una nueva identidad social y laboral, no ligada simbólicamente al mundo pampino y a la tradición salitrera. Asimismo, porque sabemos que el trabajo ofrece, ante todo, un "entorno estructurado", al que se ligan las capacidades y habilidades particulares; porque amplifica los márgenes de la vida al contrastar las actividades productivas con la esfera doméstica; porque se genera una sensación de direccionalidad en la vida, en la medida en que las actividades se orientan hacia alguna parte; otorga y configura identidad (Giddens 1999:396).

Por lo mismo, el no estar empleado en términos remunerativos o no poder constituir una identidad fincada en el trabajo como fue en el pasado, empobrece la vida social, debilita la autoestima y puede socavar la confianza de los individuos en su valor social. Así, se desdibuja la idea de la solidaridad durkheniana ${ }^{14}$; y, en su condición más extrema, se produce desafiliación social (Castel 1999). Por eso, los más antiguos y muchos de los más nuevos no tienen lugar en la Nueva María Elena, no sólo dentro de la estructura ocupacional, sino dentro de los límites físicos y no resulta, por tanto, extraño hablar de resentimientos, de degradación social e, inclusive, de cierto exilio interno, en la medida en que en este interregno se configura un tiempo cronológico, existencial y anímico que no puede ser llenado más que con la añoranza de lo que alguna vez se tuvo, especialmente la seguridad. Así como

era muy mal visto no vestirse bien, era muy mal visto no trabajar y no hacer nada [...] nadie estaba de para $[\ldots]^{15}$

Nosotros, para estas fechas [Dieciocho de Septiembre, Pascua y Año Nuevo], ya teníamos nuestro trajecito nuevo [...] de corbata iban los hombres a la retreta de la plaza [...] Ahora, lo que más se echa de menos, es la vida social ${ }^{16}$ (Figura 2).

En este sentido, el "tiempo histórico", aquel que obedece a los cambios económicos, institucionales y culturales, y en el que se inscribe el "tiempo industrial", afecta al tiempo familiar e individual. $\mathrm{Y}$ en ese marco y en estos procesos es donde se debe entender cómo los individuos y las familias definen sus prioridades y cómo revisan sus experiencias, ya que esta yuxtaposición condiciona los ritmos de vida.

A partir de la implementación de los nuevos modelos de gestión empresarial, la vida diaria carece de la estructura que les confirió el modelo de ciudad, de relaciones laborales e, inclusive, el panóptico (Rodríguez 2003). Y sin estructura aparente (porque la hay) no hay futuro ni posibilidad de imaginárselo para quienes vivieron esta antigua estructura benéfica, protectora y saturada de eventos, porque el presente se vuelve perpetuo y reiterativo en términos de repertorio de posibilidades para quienes se encuentran en una condición 


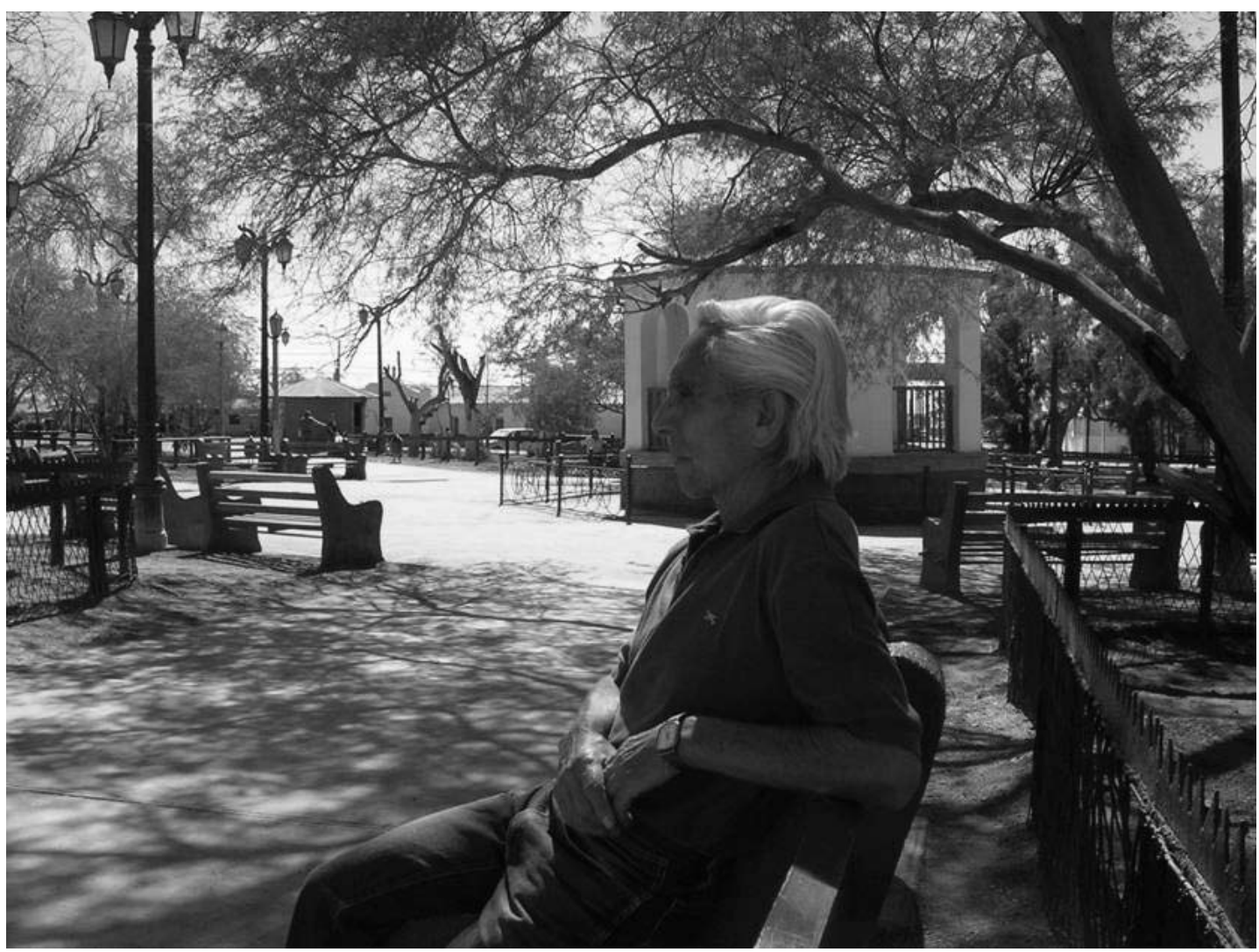

Figura 2. Plaza de María Elena.

María Elena Square.

de clausura al mundo. Pero también se vuelve perpetua y reiterativa la apelación a las instancias asistenciales, tanto en demandas cotidianas hacia la empresa SQM, a la que se siente y se piensa aún como benefactora (casi como el padre piadoso), como en apelaciones al municipio que representa la presencia del Estado.

Social y culturalmente la metamorfosis del trabajo para poblaciones especializadas y en aislamiento, como ocurre con los trabajadores del salitre de María Elena, debe entenderse también como una cierta corrosión de las fronteras, desde la mayor porosidad que caracteriza al sistema social desde que la ciudad dejó de ser sólo de los eleninos; como un cierto desborde, precariedad y vulnerabilidad en que queda o se sostiene la idea que se tiene de sí mismos, en la medida en que cuando se combinan trabajadores "estables" y "periféricos", o internos y externos, no todos son parte del mismo locus residencial ni se ligan ni reconocen en una memoria que enlaza presente y pasado, por lo que se conjuga un pool de insumos, fuerzas e intereses, juicios y prejuicios, se es receptivo de otras experiencias de vida y sociabilidad y, por cierto, de la amplificación de los códigos de conducta. Por eso, etnográficamente, la imagen de la ciudad, la profundidad de las relaciones como la percepción de sus habitantes sobre el acontecer cotidiano, es irregular y polifónica, marcada por la profundidad del vínculo establecido con el universo citadino, tal como se puede desprender del movimiento que se expresa en la Figura 3.

El espacio de intercambio y constitución de nuevos vínculos establece la generación de fuerzas conscientes e inconscientes que se expresan en el cotidiano, en la subjetividad de las personas, en el universo de lo simbólico y en el imaginario, ya que enfrenta a los individuos a un "mayor número de significados posibles en conexión con muchos objetos y situaciones", lo que afecta la conducta convencionalizada de los miembros de la comunidad (Redfield 2002:137-138). 


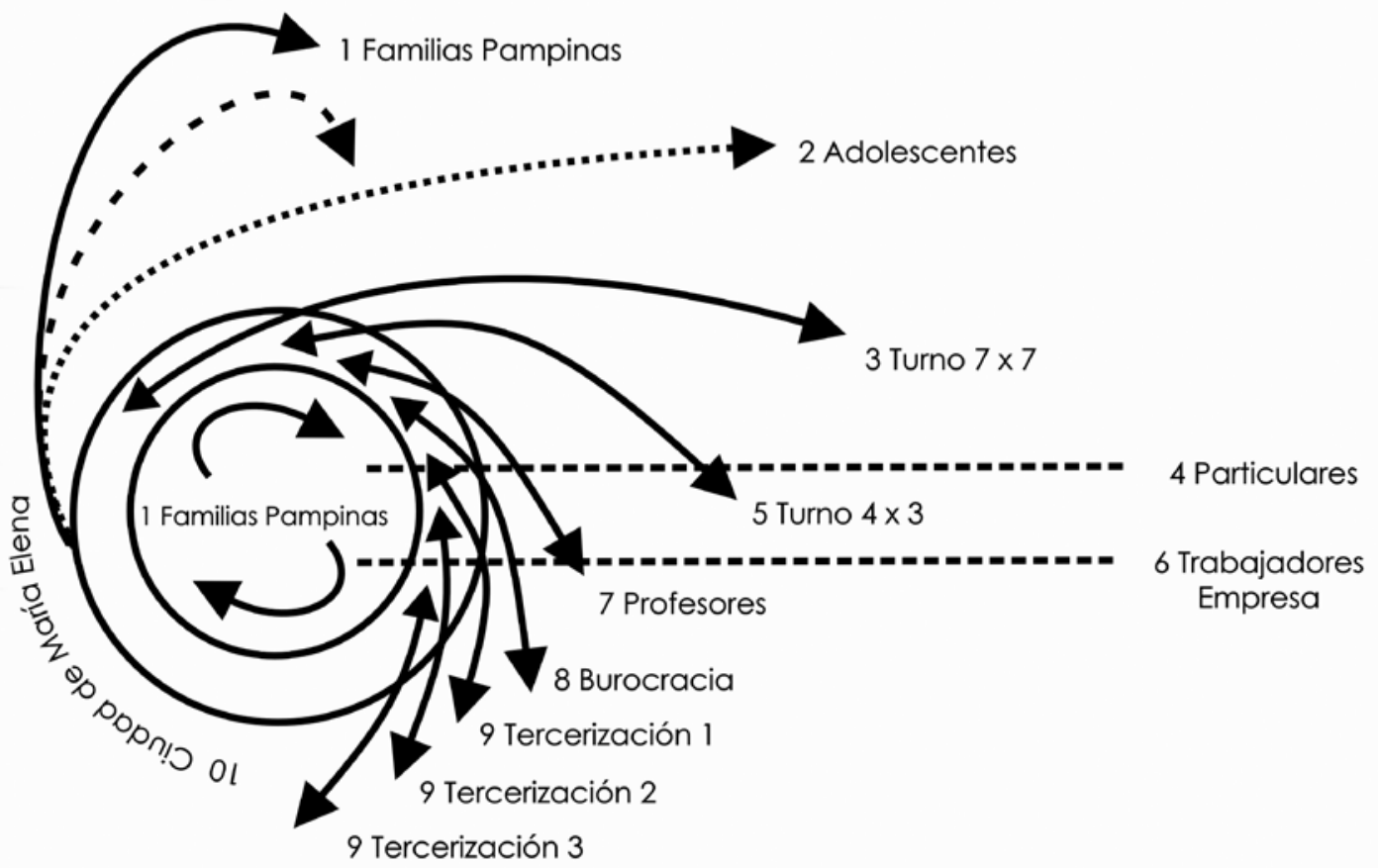

Figura 3. Actores, desplazamientos y profundidad de las relaciones con la ciudad. Actors, movements y depth of relationships whit the city.

El pueblo se echó a perder cuando llegaron los contratistas $[\ldots]$.

Los que vienen de afuera no son tan malos [...] cuentan lo que hacen y uno se entretiene escuchando. A mi me tocaron compañeros que venían de afuera... pero igual yo era bien sociable. [...] ellos cuentan cosas de la ciudad. Es rico conocer a gente que hace otras cosas; preguntarle a qué vienen [...] Para las mujeres tenían un atractivo especial [...] los de aquí son más de lo mismo [...] todos se pasan el dato [...] de cómo son, entonces se meten unos con otros [...] tuvieron algo [...] y ahí vienen los celos y las peleas $[\ldots]^{17}$

Los receptores de estas nuevas modalidades e insumos lo manifiestan como reorganización específica del tiempo y el espacio tradicional comunitario en relación a las filiaciones, emergiendo cohortes que pueden ser codificadas desde las nuevas condiciones, como en relación a cuestiones pretéritas, ya que la dinámica expansiva de la modernidad genera mutabilidad de las circunstancias y alteración de los compromisos locales, lo que conduce a muchas formas posibles de tiempo vivido (Giddens 1997) y de relaciones y compromisos vinculantes, no coincidentes con el emplazamiento minero tradicional y su carga histórica y emotiva.

Lo laboral, ahora desbordado por la emergencia de nuevos trabajadores, nuevas relaciones laborales y condiciones de producción, implica, desde el punto de vista ideológico, una ruptura de los presupuestos emocionales históricamente compartidos, ligados a lo que los hombres y mujeres de la pampa entregaron a Chile y que, además, han dado el sello de visibilidad a una identidad que desde distintos lugares se resiste a las lápidas del tiempo.

Entre estos presupuestos debilitados se manifiesta la decadencia del movimiento obrero, la diferencia paradigmática entre los contratados "empresa" y los subcontratados, la falta de solidaridad de los primeros respecto de los segundos -según confiesa un dirigente sindical-, el valor e influencia del sindicato y la desconfianza hacia las dirigencias ${ }^{18}$, en el marco de una tradición laboral que fue el crisol de utopías sociales que hablaban de la posibilidad 
de una sociedad alternativa al capitalismo, que tempranamente dio cuenta de las contradicciones entre capital y trabajo, que experimentó fáctica y discursivamente la Guerra Fría, siempre de la mano de partidos populares que marcaron el imaginario colectivo, dentro y fuera de la pampa. Asimismo, se precipita una alteración de los mecanismos a través de los cuales expresaban sus ideologías; también, una modificación drástica de la ritualidad, en la medida en que el rito de paso o iniciación, que era parte del mecanismo de socialización, del mirar hacia adentro de la pampa en una lógica donde el aprendiz podía ser maestro, deja de ser un valor que otorga y legitima socialmente. Es decir, se trastocan las formas de ver y actuar en el espacio de la "cultura laboral", porque no hay conexión entre la memoria, trabajar en la industria del salitre, el habitar la pampa y tener un lugar dentro de sus márgenes (Figura 4).

En el caso del mundo del salitre, y en el caso específico de las Oficinas Pedro de Valdivia (cerrada en 1995) y María Elena (en plena actividad), en el curso de los últimos 20 ó 25 años, se ha pasado de una comunidad en la que han coincidido lo laboral y social, de manera estable y cerrada, cuyo metabolismo se relacionaba esencialmente con los ritmos y tiempos de producción que se hacían acompañar por una vida pública activa, regulada, intensa y rica en su interior, a una donde su eje se configura a partir de la asimilación de un conjunto de elementos y aspectos que se caracterizan por la reducción de las jornadas ${ }^{19}$, la incorporación de nuevos actores con trabajos esporádicos, de una precarización de los salarios ${ }^{20}$, pérdida de prestaciones y beneficios tradicionales, $\mathrm{y}$ escasa convocatoria y fragmentación de las instituciones sociales y sindicales. Asimismo, y de manera muy consistente, se ha pasado al debilitamiento del relato del orden, tanto a nivel de las instituciones como de la ascendencia de las generaciones adultas sobre las más jóvenes que ahí mantienen su locus residencial, en la medida en que el nuevo escenario productivo implica de modo paralelo el establecimiento de mecanismos de expulsión y atracción, y sólo parcial y restrictivamente de retención para las familias con más arraigo y que se definen a sí mismas como eleninas o pampinas.

De acuerdo a lo indicado, frente a una constricción interna de plazas de trabajo por parte del principal empleador y dueño de la infraestructura, y antiguo único empleador, entre los habitantes se instala como dato duro o se fuerza tácitamente a la posibilidad de abandono del pueblo. Mientras, otros pueden llegar y seguir llegando de modo transitorio o en forma esporádica, sin ninguna historia ligada a la pampa, tal como podrían estar en cualquier parte de Chile; cuestión no menor, cuando la condición de trabajador del salitre, así como obedece o se articula con una rica memoria, también tiene su especificidad en el paisaje o en una larga permanencia.

Es esta misma abertura, este juego de mecanismos de expulsión y atracción, lo que indica que el

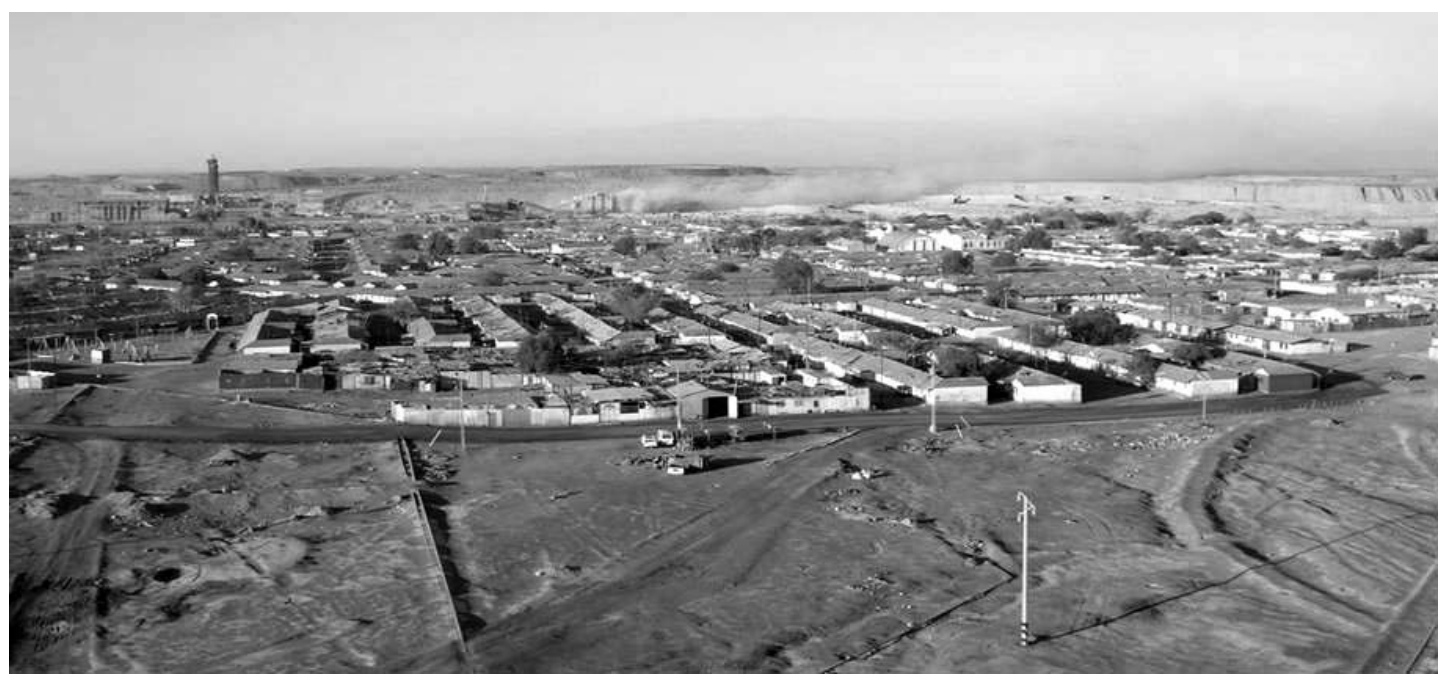

Figura 4. Vista panorámica de María Elena.

Overview of María Elena. 
pueblo ya no le pertenece sólo a quienes han vivido tradicionalmente ahí, los que son herederos o se sienten herederos de las gestas del pasado (como pioneros, colonizadores o constructores de una sociedad pampina, alimentando el erario nacional, o en relación a huelgas y hechos luctuosos), o los que dicen y se hacen llamar "eleninos" en función de la antigüedad; o, genéricamente, "pampinos", cuando se han avecindado en María Elena después de los cierres de otras oficinas.

Frente a estos fulgurantes procesos de cambio y renovación, y siguiendo la tesis de Georgio Agamben (2004), se produce una incapacidad de transmitir experiencias, es decir, del fluir de la información entre las generaciones. Esto ocurre, en la medida en que la "autoridad", la que finca la experiencia, y que se expresa en palabra y relato, tiene escasos márgenes de expresión simbólica y material y no tiene mucho sentido de realidad para los más jóvenes, ya que los insumos para hacer la vida hace mucho que tienen otras fuentes nutrientes y se fortalecen en la medida en que perfilan otras expectativas.

\section{A Modo de Cierre. Incluidos, Vulnerables y Excluidos}

Analíticamente, hoy coexisten en este espacio en el que cohabitan ciudad y campamento, los plenamente incluidos, los vulnerables y los excluidos o desafiliados ${ }^{21}$, entendiendo que las diferencias y brechas existentes entre estos se asocian a la edad, la calificación y al capital social del cual son portadores, es decir, las redes de apoyo que poseen. La amplitud de la red, en gran medida, no sólo determina el repertorio de posibilidades de quienes trabajan o pueden trabajar, sino también perfila el de los miembros no activos, como los niños y adolescentes en relación a expectativas y aspiraciones.

En términos estructurales, las posibilidades se establecen, por una parte, por la diferenciación en el nivel educativo (escolaridad) y, por otra, por la importante varianza que alcanzan los activos educativos en relación a exigencias laborales, en cuanto a la sintonía y sincronía del saber de los trabajadores y a los desarrollos tecnológicos específicos, demandados tanto por SQM como por empresas contratistas, los que se vuelven no asumibles para muchos de ellos.

Empíricamente, cada vez más honda y profunda es la acumulación de desventajas para un conjunto de trabajadores, lo que los desplaza frente a otros internos o externos, o los obliga a migrar, pensar en ello, o vivir al alero o a expensas de la ayuda social, como se ha mencionado anteriormente, o a un cierre de ojos frente a algunos pagos obligatorios que deben realizar a la empresa por concepto de arriendo, agua y luz ${ }^{22}$. En muchos casos se da una "indigencia integrada", es decir, el mínimo de integración o la desafiliación los lleva a depender de los sistemas de protección comunal como única posibilidad.

Para los desafiliados o desempleados, los reemplazantes son los externos, los de las empresas contratistas, los que no son de ningún lugar, los que son más jóvenes y están en sintonía con las nuevas tecnologías y poseen activos valorados. Para ellos, se puede afirmar, no es relevante lo que ocurra en el pueblo ni su historia, ni tienen sensibilidad respecto a las demandas cotidianas de los habitantes permanentes que revelan las dificultades de vivir en un espacio donde son cada día más exiguas las prestaciones y los servicios que durante décadas dependieron única y exclusivamente de la empresa, y que hoy son compartidos por subsidios diversos provenientes de recursos del Estado y del municipio.

En esta estratificación de pampinos y no pampinos, de internos y externos, los plenamente incluidos tienen opciones ahí en María Elena o en otros lugares, porque sus activos educativos son valorados y flexibles como para operar dentro y fuera de la industria salitrera-minera o en un abanico de compañías, aunque sin una necesaria ni obligada atención a la memoria social.

Los vulnerables son quienes viven una estabilidad precaria, ya que se encuentran en constante riesgo, entendiendo que para ellos hay escenarios diferenciados de certezas, lo que pone de manifiesto una de las cuestiones temáticamente más significativas para las ciencias sociales en la actualidad, especialmente en Latinoamérica: la desigualdad e indefensión en relación al proyecto modernizador. Más aún, cuando lo laboral como proyecto individual, y como discurso ético colectivo, implicó y se perfiló como un proceso autoconstructivo de la propia identidad y de la posición social, en el sentido de superación de las determinantes que constreñían la existencia.

La condición de vulnerable, y los grados de incertidumbre que tenga un sector de sus trabajadores, la activa la empresa SQM en relación a las necesidades 
que se tengan respecto del número requerido, a los activos educativos que se les exige o a la prescindencia de algunas áreas de trabajo en concordancia con la implementación de nuevas tecnologías, siendo muy afectados y amagados por la discontinuidad entre locus residencial y laboral. Sin embargo, esto alcanza también a funcionarios municipales administrativos, a los del área de la salud y, especialmente, a los de la educación, que se desplazan en masa a otras ciudades todos los días viernes.

De este modo, se revela que es difícil poder encontrar etnográfica y existencialmente una identidad laboral permanente y proyectarla localizadamente, donde el trabajo se exprese en forma regular, continua y durable como fue durante décadas. Asimismo, no está clara la posibilidad de que sus experticias puedan ser reconocidas más allá de María Elena, lo que instala la cuestión de la flexibilidad y redes de ayuda disponibles, especialmente para aquellos que tienen toda una vida ahí ${ }^{23}$.

Los excluidos, mientras más viejos, sólo tienen puntos de referencia hacia el pasado. No gravitan en el curso de las cosas. Tienen menos puntos de referencia espaciales y redes que permitan su acogida y salidas para enfrentar el desasosiego que implica el desarrollo tecnológico, las políticas empresariales, las comunicaciones y los activos educacionales, porque -entre otras- sus posibilidades de desplazamiento han sido históricamente menores. Aquí, se instala como armonización problemática el sino inevitable del fin de la vida y la cultura, y la imaginación que cada uno tiene de ellas. Su futuro depende fundamentalmente de factores externos, y de manera menos importantes de acciones deliberadas y de factores internos: no se conoce lo que viene para sí mismo, ni lo que le ocurrirá al prójimo.

Los incluidos, dentro de esta lógica, pueden viajar a Antofagasta o a otros lugares donde tienen sus auténticas residencias. Los vulnerables, aprendiendo de la experiencia de trabajadores de oficinas cerradas, tratan de implementar una vivienda propia en distintas ciudades si es que aún no la tienen, avizorando nuevos, cambiantes y posibles escenarios. Mientras que los excluidos, cada vez más intensamente dependen de la ayuda social.

El Nobel Albert Camus hace una reflexión atingente a esta estratificación que implica oportunidades o acumulación de desventajas. Señala él: "Cabe afirmar que si la memoria de los pobres está menos alimentada que la de los ricos, tiene menos puntos de referencia en el espacio, puesto que rara vez dejan el lugar donde viven, y también menos puntos de referencia en el tiempo de una vida uniforme y gris. Tienen, claro está, la memoria del corazón, que es la más segura, dicen, pero el corazón se gasta con la pena y el trabajo, olvida más rápido bajo el peso de la fatiga. El tiempo perdido sólo lo recuperan los ricos. Para los pobres, el tiempo sólo marca los vagos rastros del camino de la muerte" (Camus 1995:75).

Agradecimientos: A Jorge Araya Viviani, Jefe de Campamento de María Elena, por su hospitalidad. A Eduardo Ramos por su desinteresada colaboración, quien en innumerables oportunidades ha compartido su tiempo y archivo fotográfico, para este y otros trabajos.

A los habitantes de María Elena, por su siempre cálida acogida.

\section{Referencias Citadas}

Agamben, G.

2004 Infancia e Historia. Destrucción de la Experiencia y Origen de la Historia. Adriana Hidalgo Editora, Buenos Aires.

Bauman, Z.

2005 Vidas Desperdiciadas. La Modernidad y sus Parias. Editorial Paidós, Buenos Aires.

2003 Trabajo, Consumo y Nuevos Pobres. Gedisa Editorial, Barcelona.

Bioy Casares, A.

1991 La Invención y la Trama. Tusquets Editores, Barcelona.

Camus, A.

1995 El Primer Hombre. Tusquets Editores, Barcelona.
Castel, R.

1997 La Metamorfosis de la Cuestión Social. Una Crónica del Salariado. Editorial Paidós, Buenos Aires.

Compañía Salitrera Anglo Chilena 1934 Reglamento Interno para Obreros de la Cia. Salitrera Anglo Chilena.

Compañía Salitrera Anglo Chilena y The Lautaro Nitrato Co., Ltd.

1942 Reglamento Interno para Obreros de la Cia. Salitrera Anglo Chilena. y The Lautaro Nitrate Co., Ltd. (María Elena). Imprenta Macfarlane.

Durruti, A.

1993 Salitre, Harina de Luna Llena. Imprenta Norprint, Antofagasta. 
Garcés, E.

1999 Las Ciudades del Salitre. Editorial Orígenes, Santiago.

Giddens, A.

1999 Sociología. Alianza Editorial, Madrid.

1997 Modernidad e Identidad del Yo. El Yo en la Época Contemporánea. Península, Madrid.

Godelier, M.

1998 El Enigma del Don. Editorial Paidós, Buenos Aires.

González Miranda, S.

2002 Hombres y Mujeres de la Pampa. Tarapacá en el Ciclo de Expansión del Salitre. LOM Ediciones, Universidad Arturo Prat y Centro de Investigaciones Diego Barros Arana, Santiago.

2006 El mundo de las casas de lata. La vida en la pampa salitrera. En Historia de la Vida Privada en Chile. El Chile Moderno de 1840-1995. Tomo II, pp. 187-213. Bajo la dirección de Rafael Sagredo y Cristián Gazmuri. Editorial Taurus, Santiago.

González Pizarro, J.

2003 La pampa Salitrera en Antofagasta. Auge y ocaso de una era histórica. La Vida Cotidiana Durante los Ciclos Shanks y Guggenheim en el Desierto de Atacama. Ediciones Proa, Antofagasta.

Gorz, A.

1991 Méthamorphoses du Travail (Critique de la Raison Économique). Galilée, Paris.

Guadarrama, R.

2002 La cultura laboral. En Tratado Latinoamericano de Sociología del Trabajo, coordinado por E. de la Garza Toledo, pp. 213-237. Colegio de México, FLACSO, UAM y FCE, México.

Guerrero, V.

1998 Minería y asentamientos humanos: los campamentos mineros en la provincia de Iquique. Revista de Ciencias Sociales 8:17-33. UNAP, Iquique.

Hernández, R.

1930 El Salitre. Resumen Histórico desde su Nacimiento y Explotación. Fisher Hermanos, Valparaíso.
INE

2006 Censos de población 1992/ 2002. http: //www.infopaís.cl Mahfuz, N.

2002 Amor Bajo la Lluvia. Ediciones Destino, Barcelona.

Ministerio de Vivienda y Urbanismo

2006 www.observatoriourbano.cl. Ministerio de Vivienda y Urbanismo - Chile

Miranda Bown, P. y J.C. Rodríguez Torrent

2006 Beautiful losers. Manuscrito en posesión de los autores.

Redfield, R.

2002 Antropología sin Fronteras, compilado por A.B. Pérez Castro, M. Ochoa Ávila y M. Soriano Pérez, Tomo I, Instituto de Investigaciones Antropológicas de la Universidad Nacional Autónoma de México, Fideicomiso para la Cultura México/ USA, Fundación Rockefeller, Fundación Cultural Bancomer, Fondo Nacional para la Cultura y las Artes. México.

Revista Pampa. Por qué vivimos como vivimos $\mathrm{N}^{\circ} 58$ : 2-42, enero 1953, Editorial Zig-Zag, Santiago, Chile

Rodríguez Torrent, J.C.

2001 La mala memoria y la muerte feliz en María Elena, un pueblo salitrero en el desierto de Atacama, Chile. Revista Antropológica 18:67-75. Universidad Nacional Autónoma de México, México.

2003 La reinvención del paraíso: sueño y olvido en los habitantes de los últimos pueblos salitreros del desierto de Atacama, Chile. En Desierto y Fronteras. El Norte de México y Otros Contextos Culturales. V Coloquio Paul Kirchoff. Editado por Hernán Salas y Rafael Pérez-Taylor, pp. 123-152. Universidad Nacional Autónoma de México, Instituto de Investigaciones Antropológicas y Plaza y Valdez, México.

Rodríguez Torrent, J.C., P. Miranda B. y P. Mege

2005 Réquiem para María Elena. Notas sobre el imaginario de los últimos pampinos. Estudios Atacameños 30:149-67.

Kunza Consultores

(s/f) Actualización Plan de Desarrollo Comuna de María Elena. Código B.I.P. 20150133-0.

SQM

2006 Memoria Social 2005-2006. SQM, Santiago.

\section{Notas}

1 Este trabajo es producto del Proyecto Fondecyt 1060092, "María Elena. cambio y reestructuración cultural. Una cartografía antropológica de sus marcadores".

2 Véase para estas cifras el documento Actualización Plan de Desarrollo Comuna de María Elena, aunque este no explica que la diferencia de casi 4.000 personas entre el año 1992 y 1996 se debe a que ya se había iniciado el traslado de algunas secciones de trabajadores desde Pedro de Valdivia a María Elena. Sin embargo, el INE estima para el año 2.015 una población de 2.706 habitantes, lo que la situaría por debajo de una condición de ciudad, o en el límite para mantenerse como tal.

3 La cifra, además, da cuenta de que en el presente, alrededor de un tercio de los alumnos corresponde a Enseñanza Media y, entre éstos, entre el 2005 y 2006 se perdieron casi 60 cupos, disminuyendo la matrícula de 434 a 373 (Información proporcionada por el Sr. Williams Buttler, Director de
Educación Municipal). Asimismo, la capacidad instalada del sistema educacional es superior a las necesidades.

4 Fuente: SQM.

5 Véanse Reglamento Interno para Obreros de la Cía Chilena Anglo Lautaro (1934), Compañía Salitrera Anglo Chilena y The Lautaro Nitrato Co., Ltd. (1942), o Reglamento vigente para Staff, de SQM.

6 Registro realizado en la primavera de 2006.

7 Recuérdese que, tal fue la importancia de la industria del salitre en términos de movimiento de capitales y fuerza de trabajo, que en 1880, cuando el presupuesto nacional era de 124,6 millones de pesos, el erario recibía por concepto de impuestos de exportación de salitre 6,8 millones, equivalente al 5,52\%; Luego, en 1890, cuando el presupuesto era de 201,9 millones, las arcas del fisco recibían 105,1 millones por dicho concepto, alcanzando al 52\%; Más tarde, en 1916, y ya acercándose al desarrollo de la industria del salitre 
sintético, las cifras por el pago de impuestos llegó a ser el 60\% del presupuesto (Hernández 1930, 177-178; Revista Pampa $\mathrm{N}^{\circ}$ 58, de 1953).

$8 \quad$ El Reglamento Interno del Staff de Solteros, señala: "La asignación de pieza es de carácter INDIVIDUAL, por lo tanto el trabajador no podrá incorporar como parte de la asignación a su esposa, hijos, parientes o amistades en general"

9 White, Anglo, Saxon, Protestant.

10 Cuestión que debe ser considerada única en Chile.

11 Fuente: Ilustre Municipalidad de María Elena.

12 Se indica claramente en las oficinas del campamento: "la empresa no es rentista.... ése no es su rubro". Asimismo, existe un régimen especial para los profesores, los cuales no cancelan por concepto de arriendo y son subvencionados en relación al consumo de agua y luz, pagando sólo si se exceden en lo establecido.

13 La empresa SQM, inclusive, ha ofrecido entregarles una libreta de postulación a la vivienda con ahorro previo para desocupar esta instalación precaria y peligrosa.

14 Nos referimos a la solidaridad orgánica, diferenciada y complementaria donde la acción de todos permite el desempeño personal.

15 Testimonios recogidos en el trabajo de campo, los que se repiten con extrema regularidad entre los antiguos trabajadores y jefes y jefas de hogar.

16 Registros de campo realizado en septiembre de 2006, a una profesora con 30 años de servicio entre Pedro de Valdivia y María Elena.
17 Testimonio recogido en María Elena, el otoño del 2006.

18 "Estos no son dirigentes sindicales. Los auténticos son los que están en el cementerio. Los que mataron. Estos de ahora, cuando negocian lo hacen en las termas, y después se llevan a las familias de vacaciones" (registros realizados en invierno de 2004)

19 Por ejemplo, la introducción de un sistema de turnos de 7 días activos por 7 de descanso en algunas áreas productivas, acaba con las horas extraordinarias que ayudaban a elevar los salarios.

20 Aun cuando estadísticamente los salarios pueden considerarse altos. La encuesta CASEN del año 2000 daba un promedio de ingreso autónomo mensual de 467.574 (véase Censo, informaciones de la empresa).

21 Hacemos nuestra la distinción realizada por Robert Castel (1999), entre excluidos y desafiliados, entendiendo que los primeros quedan atrapados en una cierta inmovilidad, mientras que los segundos tienen una trayectoria que los ha conducido a la desventaja.

22 Por ejemplo, hay jubilados que reciben 92.000 , y deben pagar a la empresa entre 50.000 y 60.000 por concepto de arriendo, más lo que corresponde al $50 \%$ del consumo de agua y luz. En este sentido, la deuda asociada a personas no activas y no ligadas a la empresa con ésta, se convierte en una suma altísima e impagable, la que se abulta día a día.

23 Es fácil encontrar personas que no pueden financiar un boleto de bus para trasladarse a Tocopilla, sólo para realizar un trámite. 
